This document is published in:

Economics Letters, (2007), 88 (2), 203-208.

DOI: http://dx.doi.org/10.1016/j.econlet.2005.01.019

(C) 2005 Elsevier B.V. 


\title{
Market structure, scrappage, and moral hazard
}

\author{
Susanna Esteban ${ }^{\mathrm{a}}$, Gerard Llobet ${ }^{\mathrm{b}, *}$

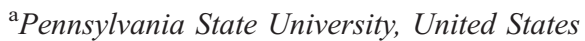 \\ ${ }^{\mathrm{b}}$ CEMFI, Spain
}

\begin{abstract}
In the presence of moral hazard, the optimal contract for a durable-goods monopolist is a lease with an option to buy. This contract is optimal regardless of the monopolist's ability to commit and creates inefficient scrappage.
\end{abstract}

Keywords: Monopoly; Moral hazard; Scrappage; Maintenance; Durability

JEL classification: L11; L12

\section{Introduction}

When the life of a durable good depends on the maintenance effort of the consumer, the contract offered by its supplier can affect the consumer's behavior. If the good is rented, its life will be shortened, because the consumer cares only about the short-run effects of her maintenance decisions. If the good is sold, its durability is enhanced, because the consumer then internalizes the long-run returns to her effort.

In the presence of moral hazard, a monopolistic supplier can discriminate amongst different consumer types by offering a lease with an option to buy. Those consumers with a higher cost of effort will rent a new unit every period, while the remaining ones exert effort and exercise the option to buy. The monopolist can use the option price as a means to capture part of the consumers' surplus from exerting effort, but it does so at the expense of creating inefficient scrappage.

* Corresponding author. Tel.: +34 914290 551; fax: +34 914291056.

E-mail address: 1lobet@cemfi.es (G. Llobet). 
The effect of maintenance decisions on a durable-goods monopolist problem has been studied in the literature. Hendel and Lizzeri (1999b) and Morita and Waldman (2004) show that a monopolist can increase its profit by either restricting maintenance or controlling this market directly. Achter (2000) finds that a lease can implement the first best when consumer's effort in maintenance is not observable and consumers are sufficiently heterogenous in their willingness to pay. ${ }^{1}$

Schmalensee (1974) shows that a rental contract is preferable to an outright purchase when maintenance by the monopolist is technically feasible. The logic is straightforward. If the good is sold, the monopoly price of the good will exceed the marginal cost of production. As a result consumers will overinvest in maintenance as compared to its efficient level. Instead, the monopolist can increase its profits by renting the good and directly performing the efficient level of maintenance. In our paper, maintenance is always controlled by the consumer. However, the monopolist can influence the level of maintenance by adjusting the price of the option to buy. If the price differential between leasing a new good and exercising the option to buy equals the marginal cost of producing the new good, maintenance will be efficient. But given the efficient price differential, the monopolist will garner the same profit from those consumers who exercise the option to buy as from those who do not. Consumers who exert maintenance effort and then exercise the option to buy will retain all of the surplus from their maintenance decisions. If consumers are heterogeneous, however, the monopolist will be able to capture part of this surplus by increasing the option price. In that event, consumers may fail to exercise their option to buy even when it would be efficient to do so, and premature scrappage may result as a consequence.

Finally, Bulow (1982) shows that renting emerges as the optimal contract when the monopolist cannot commit to future prices since it resolves the time consistency problem of the firm. In our model, a lease (in which some consumers exercise the option to buy) is optimal even if the firm cannot commit to future prices. The intuition is that when the monopolist raises the option price to price discriminate consumers, it also makes the contract time-consistent, because it obtains a higher profit from those consumers exercising the option to buy than from those who lease another new good.

\section{Model}

A full-commitment monopolist produces a semi-durable good and chooses the optimal contract to offer to consumers. The good depreciates at a rate that depends on the consumer's effort to maintain it. Consumers differ in their disutility from exerting effort, which, together with the outcome of their effort, is private information. Therefore, the contract that the monopolist offers can only specify payments that depend on the time period and whether the good is new or used, which then falls in the general class of leasing contracts.

The time horizon is two periods. A lease is a pair $\left(p_{t}, q_{t}\right)$, where $p_{t}$ is the rental price and $q_{t}$ is the price paid for exercising the option to buy in $t+1$. With two periods, the contracts are $\left(p_{1}, q\right)$ and $\left(p_{2}\right)$. Note that if $q=\infty$, the contract is a simple rental contract since the used good is always

\footnotetext{
${ }^{1}$ Leasing also arises as the optimal contract in other environments. Hendel and Lizzeri (1999a), Hendel and Lizzeri (2002), and Johnson and Waldman (2003) provide explanations based on adverse selection. Waldman (1999) explores the role of moral hazard with perfect competition and adverse selection. Desai and Purohit (1998) show that when leased and sold goods have different exogenous depreciations, a monopolist can price discriminate better by offering both contracts.
} 
returned to the monopolist. If $q=0$, the contract is a sales contract since exercising the option to buy is free. ${ }^{2}$

Consumers differ in their cost of exerting maintenance effort, which we parameterize by $\theta$. In $t=1$, each consumer-type $\theta$ decides whether or not to lease a new good and the level of effort she exerts in maintaining it. By exerting effort $e \in[0,1]$, the consumer yields a used good in $t=2$ that has flow of services of $\alpha e$, where $\alpha \in(0,1)$.

The utility function for a consumer at time $t$ is given by $s-p_{t}-\psi(e, \theta)$, where $s$ is the flow of services for the good consumed in $t, p_{t}$ is its price, and $\psi(e, \theta)$ is the utility cost for type $\theta$ of exerting effort $e$. We assume $\psi(0, \theta)=0, \psi_{1}>0, \psi_{2}>0$, and $\psi_{12}>0$. In other words, zero effort is costless, utility cost is increasing in effort and type, and there is complementarity between $e$ and $\theta$, so that consumers with lower $\theta$ incur a lower marginal cost from exerting effort. Then, a type- $\theta$ consumer derives utility of $\max \left\{1-p_{1}-\psi(e, \theta), 0\right\}$ in $t=1$ and $\max \left\{1-p_{2}, \alpha e-q, 0\right\}$ in $t=2 .^{3}$

We assume $\theta \in[0,1]$ is distributed according to $F(\theta)$ with density function $f(\theta)$, and we normalize the mass of consumers to 1 . We let $c<1$ denote the marginal cost of production and $\delta \in[0,1]$ denote the discount factor.

Given $\left(p_{1}, q\right)$ and $\left(p_{2}\right)$, type $\theta$ leases a new good in $t=1$ if

$$
1-p_{1}+\max \left\{-\psi\left(e^{*}(\theta), \theta\right)+\delta\left(\alpha e^{*}(\theta)-q\right), \delta\left(1-p_{2}\right), 0\right\} \geq 0,
$$

and exerts effort if

$$
-\psi\left(e^{*}(\theta), \theta\right)+\delta\left(\alpha e^{*}(\theta)-q\right) \geq \max \left\{\delta\left(1-p_{2}\right), 0\right\},
$$

where

$$
e^{*}(\theta)=\operatorname{argmax}_{e} 1-p_{1}-\psi(e, \theta)+\delta(\alpha e-q) .
$$

Our assumptions on $\psi$ imply that $e^{*}(\theta)$ is decreasing in $\theta$ (higher types exert less effort) and is independent of prices. The latter implies that when effort is exerted, the level of effort will be independent of market structure.

Let $\hat{\theta}=\hat{\theta}\left(p_{2}, q\right)$ be the threshold level of $\theta$ that makes Eq. (2) an equality, so that

$$
-\psi\left(e^{*}(\hat{\theta}), \hat{\theta}\right)+\delta\left(\alpha e^{*}(\hat{\theta})-q\right)=\max \left\{\delta\left(1-p_{2}\right), 0\right\} .
$$

Then, a type- $\hat{\theta}$ consumer will be indifferent between exerting effort and not. As a result, the demand function for new goods in each period is given by

$$
D_{1}\left(p_{1}, p_{2}, q\right)= \begin{cases}1 & \text { if } p_{1} \leq 1 \\ F\left(\hat{\theta}\left(p_{2}, q\right)\right) & \text { otherwise }\end{cases}
$$

\footnotetext{
${ }^{2}$ Hendel and Lizzeri (2002) also make this distinction.

${ }^{3}$ The assumption that consumers are identical in the utility they derive from consumption makes the secondary market inactive by eliminating any gains from trade.
} 
and,

$$
D_{2}\left(p_{2}, q\right)= \begin{cases}1-F\left(\hat{\theta}\left(p_{2}, q\right)\right) & \text { if } p_{2} \leq 1, \\ 0 & \text { otherwise }\end{cases}
$$

respectively, while second period scrappage equals $1-F\left(\hat{\theta}\left(p_{2}, q\right)\right)$.

We also require that at least for the consumers with the lowest cost of effort, maintenance is socially optimal,

$$
\delta(1-c) \leq \delta \alpha e^{*}(0)-\psi\left(e^{*}(0), 0\right) .
$$

\subsection{First best}

In a full-information, competitive equilibrium, $p_{1}=c, q=0$, and $p_{2}=c$. Since $p_{1}<1$, all consumers buy a new good in $t=1$ and types $\theta \leq \hat{\theta}_{c}$ maintain it, where $\hat{\theta}_{c}$ solves

$$
-\psi\left(e^{*}\left(\hat{\theta}_{c}\right), \hat{\theta}_{c}\right)+\delta\left(\alpha e^{*}\left(\hat{\theta}_{c}\right)-0\right)=\delta(1-c) .
$$

By Eq. (7), not all used goods are scrapped. Note that a comparison of Eqs. (4) and (8) implies that

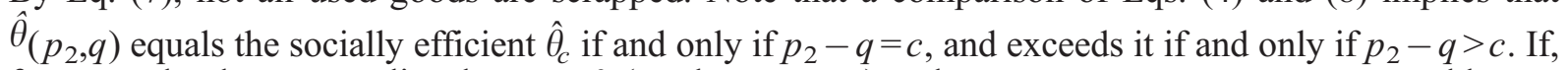
for example, the monopolist chose $q=0$ (a sales contract) and $p_{2}>c$, too many consumers would exert effort because the replacement cost in $t=2$ would exceed the marginal cost of production, which would make scrappage lower than its socially efficient level. This result is similar to the one found in Schmalensee (1974) that shows that a monopolist earns more profit by renting the good, and performing efficient maintenance himself, than by selling it. Although in our model, maintenance must be performed by the user, the monopolist can modify maintenance decisions by use of the option price: for example, by setting $p_{2}=1$ and $q=1-c$ (which implies $p_{2}-q=c$ ), the choice of maintenance by consumers is socially efficient. We next show that although efficient maintenance is feasible for the monopolist, it is not profit-maximizing.

\subsection{Monopolist}

We first solve for the monopolist's optimal contract with full commitment.

Given Eqs. (4)-(6), the monopolist's problem is given by

$$
\max _{p_{1}, q, p_{2}} D_{1}\left(p_{1}, q, p_{2}\right)\left(p_{1}-c\right)+\delta\left[F\left(\hat{\theta}\left(p_{2}, q\right)\right) q+D_{2}\left(p_{2}, q\right)\left(p_{2}-c\right)\right] .
$$

Proposition 1. For the full-commitment monopolist, the optimal contract is $p_{1}=1, q=\alpha e^{*}\left(\hat{\theta}_{m}\right)-1 /$ $\delta \psi\left(e^{*}\left(\hat{\theta}_{m}\right), \hat{\theta}_{m}\right)$, and $p_{2}=1$, where $\hat{\theta}_{m}$ solves

$$
\delta\left[\alpha e^{*}\left(\hat{\theta}_{m}\right)-\frac{1}{\delta} \psi\left(e^{*}\left(\hat{\theta}_{m}\right), \hat{\theta}_{m}\right)-(1-c)\right] f\left(\hat{\theta}_{m}\right)-\psi_{2}\left(e^{*}\left(\hat{\theta}_{m}\right), \hat{\theta}_{m}\right) F\left(\hat{\theta}_{m}\right)=0 .
$$


Proof. We only need to consider $p_{1}=1$ and $p_{1}>1$ in Eq. (5). (If $p_{1}<1$, sales are the same as with $p_{1}=1$.) Take as given $p_{2}=1$ (which follows from the consumers' willingness to pay for a new good being 1 in $t=2$ ) and $q$. These define a unique critical type in Eq. (4). If $p_{1}=1$, the discounted profit equals $(1+\delta q-c) F(\hat{\theta})+(1+\delta)(1-c)(1-F(\hat{\theta}))$. Instead, if $p_{1}>1$, the discounted profit equals $(1+\delta q-c) F(\hat{\theta})+\delta(1-c)(1-F(\hat{\theta}))$. Comparing these two expressions, $p_{1}=1$ is optimal. Then, substituting $p_{1}=1$ in the demand equation (Eq. (5)) and using Eq. (4) to solve for $q$, we can rewrite the monopolist's problem as

$$
\max _{\hat{\theta}_{m}}\left[1-\psi\left(e^{*}\left(\hat{\theta}_{m}\right), \hat{\theta}_{m}\right)+\delta \alpha e^{*}\left(\hat{\theta}_{m}\right)-c\right] F\left(\hat{\theta}_{m}\right)+(1-c)(1+\delta)\left(1-F\left(\hat{\theta}_{m}\right)\right) .
$$

Then, the first order condition and the envelope theorem yields Eq. (10).

Eq. (10) implies that the optimal option price is

$$
q=1-c+\frac{\psi_{2}\left(e^{*}\left(\hat{\theta}_{m}\right), \hat{\theta}_{m}\right) F\left(\hat{\theta}_{m}\right)}{\delta f\left(\hat{\theta}_{m}\right)}>1-c
$$

where $\psi_{2}>0$ establishes the inequality. This result implies that $p_{2}-q=1-q<c$ and $\hat{\theta}_{c}$ exceeds $\hat{\theta}_{m}$, creating more scrappage than it is socially optimal.

Corollary 1. The optimal contract in Proposition 1 creates inefficient scrappage.

The intuition is that when $q=1-c$ (which implies $p_{2}-c=q$ ), types $\theta<\hat{\theta}_{c}$ keep all the surplus from their maintenance effort since the monopolists profit per unit sold simply equals the profit from renting the good. To capture part of this surplus, the monopolist raises the option price, but it does so at the expense of creating inefficient scrappage.

Proposition 2. The optimal contract in Proposition 1 is time consistent.

Since $q>1-c$, the option price is more profitable than the highest price the monopolist can charge in $t=2\left(p_{2}=1\right)$, and the monopolist never revises its choice for $p_{2}$. Corollary 1 also applies.

Remark 1. With full commitment, the monopolist can offer two contracts in $t=1, A$ and $B$, such that $p_{1}^{A}=1, q_{1}^{A}=\infty, p_{1}^{B}>1$, and $q_{1}^{B}=\frac{\left.1-p_{1}^{B}-\psi e\left(\hat{\theta}_{m}\right), \hat{\theta}_{m}\right)+\delta \alpha e^{*}\left(\hat{\theta}_{m}\right)}{\delta}$. Contract $A$ rents the good, while $B$ sells it at a price of $p_{1}^{B}+\delta q_{1}^{B}$. This sale price plays the same role as $1+\delta q$ did in Proposition 1 and thus the monopolist accrues identical profits. For a small fixed cost of offering a contract, the two contracts defined here are dominated by the single contract in Proposition $1 .{ }^{4}$

Remark 2. Without moral hazard (i.e., if the quality of a used good was observable), the monopolist could condition the option price on the observed quality and improve its profit beyond Proposition 1 by offering a family of contracts.

\footnotetext{
4 This remark does not apply to the non-commitment problem: with a lower option price, the monopolist might prefer revising $p_{2}$.
} 


\section{Acknowledgements}

We are grateful to Kalyan Chatterjee and Michael Manove for useful comments and especially to Eric Bond for a very helpful suggestion.

\section{References}

Achter, B., 2000. Durable Goods and Moral Hazard: An Option to Implement the First Best, mimeo.

Bulow, J., 1982. Durable-goods monopolists. Journal of Political Economy 90, 314-332.

Desai, P., Purohit, D., 1998. Leasing and selling: optimal marketing strategies for a durable goods firm. Management Science $44,19-34$.

Hendel, I., Lizzeri, A., 1999a. Adverse selection in durable goods markets. American Economic Review 89, 1097-1115.

Hendel, I., Lizzeri, A., 1999b. Interfering with secondary markets. Rand Journal of Economics 30, 1-21.

Hendel, I., Lizzeri, A., 2002. The role of leasing under adverse selection. Journal of Political Economy 110, 113-143.

Johnson, J., Waldman, M., 2003. Leasing, lemons, and buybacks. Rand Journal of Economics 34, 247-265.

Morita, H., Waldman, M., 2004. Durable goods, monopoly maintenance, and time inconsistency. Journal of Economics and Management Strategy 13, 273-302.

Schmalensee, R., 1974. Market structure, durability, and maintenance effort. Review of Economic Studies 41, 277-287.

Waldman, M., 1999. Leasing, Lemons and Moral Hazard, mimeo. 